\title{
JUDICIALIZACIÓN DE LA POLÍTICA Y MORALIZACIÓN DEL DERECHO, UN RETO PARA LOS CONSULTORIOS JURÍDICOS EN COLOMBIA
}

\author{
Alonso Cortina Acevedo ${ }^{1}$
}

\section{Resumen}

Este ensayo reflexivo trato de presentar la judicialización de la Política y la moralización del derecho, como un reto para los consultorios jurídicos en la medida en que son dos fenómenos que representan un giro copernicano en cuanto a la práctica del derecho, toda vez que, exigen que el abogado en Colombia, asuma por ideología constitucional la carga de pensar las soluciones de la peor crisis Política que haya podido atravesar el país en su historia reciente, es así, que actualmente el abogado debe tener las competencias necesarias para resolver conflictos utilizando la Constitución Política como norma, es decir, debe ser competente en el dominio de la axiología y la política en su total complejidad, la cual se manifiesta desde el que hacer de la enseñanza y práctica de éstas disciplinas como ciencias sociales. A través de una investigación jurídica, descriptiva con un enfoque cualitativo, cuyo objetivo y problema jurídico se centró en la búsqueda de la justicia y protección de los derechos fundamentales, frente a la judicialización de la política y moralización del derecho, como un reto para los Consultorios Jurídicos en Colombia, el cual se verá en ocasiones abocado a apartarse de la ley dando un salto argumentativo para afianzar su decisión basada en la Constitución. Cuya investigación arrojo como conclusión, que la formación del abogado debe procurar una práctica en la que se desarrollen

1 Abogado, Especialista en Derecho Administrativo, Especialista en Administración Pública, Doctorando en Ciencias Políticas, Jefe del Consultorio Jurídico de la Escuela de Derecho de la Universidad del Sinú, Docente Investigador adscrito al Grupo de Investigación Sociedad y Conflicto de la Escuela de Derecho de la Universidad del Sinú Sede Cartagena. Email: acortinaa@unisinucartagena.edu.co 
competencias en torno a la teorización sistematizada de la relación entre la política y la axiología.

Palabras clave: Judicialización de la política, moralización del derecho, formación política, formación axiológica y Consultorio Jurídico.

\section{Abstract}

This reflective essay tries to present the judicialization of politics and the moralization of law as a challenge for legal offices insofar as they are two phenomena that represent a Copernican turn in the practice of law, since they demand that the lawyer in Colombia assumes, as a constitutional ideology, the burden of thinking about the solutions to the worst political crisis the country could have gone through in its recent history, It is thus, that currently the lawyer must have the necessary competences to solve conflicts using the Political Constitution as a rule, that is, he must be competent in the domain of axiology and politics in its total complexity, which is manifested from which to make the teaching and practice of these disciplines as social sciences. Through a legal research, descriptive with a qualitative approach, whose objective and legal problem was focused on the search for justice and protection of fundamental rights, as opposed to the judicialization of politics and moralization of law, as a challenge for the Legal Clinics in Colombia, which will sometimes be forced to depart from the law by making a leap in argument to strengthen their decision based on the Constitution. The conclusion of my research is that the training of lawyers should seek a practice in which they develop skills in the systematic theorization of the relationship between politics and axiology.

Keywords: Judicialization of politics, moralization of law, political education, axiological training, legal consulting.

\section{Introducción}

Con la Constitución de 1991, el advenimiento del Estado Social de Derecho, la globalización, y el Neoconstitucionalismo de la Corte Constitucional colombiana, se produjo un fenómeno de constitucionalización del derecho y judicialización de la Política, que rompió con los paradigmas que históricamente habían marcado la enseñanza del derecho. Las dinámicas sociales que han caracterizado la modernidad última vienen marcadas por un cambio de paradigma de la relaciones entre 
Estado, sociedad e individuo, hoy cada vez con mayor contundencia el individuo adquiere mayor autonomía frente a la sociedad y frente al Estado, convirtiéndose incluso en sujeto de derecho internacional, la globalización como fenómeno económico, político y cultural viene debilitando el Estado y su capacidad para garantizar una sana convivencia en condiciones de paz, equidad y justicia, esto en la medida en que las fuerzas del mercado internacional, banca internacional, el derecho humanitario, el sistema internacional de protección de los derechos humanos entre otros factores, condicionan las decisión que internamente debe tomar el gobierno de cada Estado restándoles soberanía y condicionándoles la Política pública en materia social, económica etc.

La ideología Neoconstitucional o "nuevo derecho" con la cual la Corte Constitucional interpreta hoy la Constitución Política de los colombianos, ha producido una verdadera constitucionalización del ordenamiento jurídico, en la medida en que no hay conflicto de la realidad nacional que se sustraiga de la posibilidad eventual de que le sea aplicada directamente la Constitución nacional como norma de solución, sin importar a que ámbito del derecho pertenece la situación de conflicto, sea público o privado, todo el derecho está sometido a la supremacía constitucional, tanto es así que hoy se habla por ejemplo del nuevo derecho internacional de los contratos (Parra R, 2002).

El Neoconstitucionalismo o nuevo derecho se caracteriza, entre otras cosas, por el papel protagónico del poder judicial, es así, que en un escenario Neoconstitucional, el juez funge como legislador positivo en la medida en que emite sentencias que contienen subreglas que como fuente originaria de derecho entran a regular la solución de conflictos como si fueran ley, pero además, el juez constitucional también ejerce acciones de gobierno en la medida en que con sus sentencias direcciona y condiciona la Política público del ejecutivo, esto, desde el "nuevo derecho" se justifica entre otras cosas, según Gonzalo Aguilar Cavallo por La desigualdad socio-económica, la desigualdad de oportunidades, pero también la desigualdad jurídica, asunto que según Aguilar incide en la libertad y en el bienestar de las personas y comunidades, permeando su calidad de vida en distintos sentidos (Gonzalo, 2015). Lo anterior, cobra especial relevancia cuando asumimos que la riqueza de las personas depende enormemente de las leyes que se hayan promulgado en su comunidad (Dworkin, 1997). Es por eso que en sociedades altamente desiguales vale la pena preguntarse si acaso el juez debería concebirse como el último reducto que el Estado de Derecho le asegura al individuo 
y a las comunidades para alcanzar condiciones sociales mínimas justas en el pleno ejercicio de todos sus derechos humanos consagrados nacional e internacionalmente. En esta línea, se ha planteado un nuevo rol del juez del siglo XXI como garante de los derechos humanos.

El fortalecimiento del poder judicial como alternativa de solución de los grandes conflictos sociales escenario de la recurrente violación de derechos humanos, ha llevado a la judicialización de la Política, fenómeno en el cual, la sociedad comienza a legitimar el juez constitucional como una autoridad con el poder suficiente de hacer cumplir la Constitución imponiéndose a los desprestigiados órganos representativos del poder legislativo y ejecutivo, esta facultad exige del juez no sólo un despliegue de conocimiento y competencias en el dominio de la ciencias jurídicas, sino que ahora también debe tener una sólida formación en ciencias Políticas dice García Jaramillo (2008):

El juez del nuevo derecho puede y, más que eso, debe, determinar en casos concretos la existencia de derechos no contemplados explícitamente en el ordenamiento, por lo que requiere una mayor profundidad moral, Política y social para desempeñar su función; debe ser más fuerte y ya no solamente el burócrata, y admite abiertamente que es él quien decide, y no la ley. Este juez deberá responder más directamente sobre las implicaciones Políticas y sociales de sus decisiones, sin poder pasarle a otro tercero la responsabilidad del fallo, y administrará efectivamente justicia de-construyendo los mandatos constitucionales, caracterizados por la textura abierta de sus normas y la diversidad de sus formas.

Así las cosas, el juez en el "nuevo derecho" en la búsqueda de la justicia y protección de los derechos fundamentales, se verá en ocasiones abocado a apartarse de la ley dando un salto argumentativo para asir su decisión a la Constitución, claro que Tal como lo afirma Leonardo Jaramillo para llegar a esta conclusión y definir claramente qué normas y en qué casos, debe apartarse de la ley por ser ésta contraria a la autoridad de la Constitución, los jueces tienen que tener competencias propias de la ciencia Política que le permitan argumentar su visión de la realidad dando significado a la democracia, la justicia y su relación con el Estado la sociedad y el derecho, para poder legitimar constitucionalmente su particular interpretación de la Constitución. 


\section{Judicialización del derecho como fenómeno asociado al Neoconstitucionalismo}

El fortalecimiento del poder judicial como fórmula práctica de defensa de los derechos fundamentales trae consigo el fenómeno de la judicialización de la Política, el cual está asociado con la falta de credibilidad y acción Política del poder ejecutivo y del poder legislativo, en la medida en que los conflictos que socialmente deben encontrar solución Política en el parlamento con la ley y en el Ejecutivo con el diseño y ejecución de Políticas públicas, son finalmente resueltos mediante sentencia por la jurisdicción constitucional, esto, si bien es cierto, trae consigo unos beneficios también puede acarrear falta de legitimidad y desinstitucionalización del poder judicial por cuenta de la posibilidad de graves abusos en los que puede incurrir un juez constitucional dado el alto grado de discrecionalidad de sus decisiones, las cuales como se dijo anteriormente, pueden legitimante, apartarse del marco reglado y previsible de la ley para centrarse o justificarse en la indeterminación de los principios y valores de la Constitución. Al respecto se pregunta el constitucionalista Uprimny (2007) ¿Cuáles son las potencialidades democráticas y los riesgos de la judicialización?, ante lo cual, esquematiza la judicialización de la Política como una modificación de las fronteras tradicionales entre el sistema judicial y el sistema político en las sociedades democráticas, "en la medida en que el trámite y la decisión de ciertos asuntos son transferidos de la esfera Política al ámbito judicial" (Uprimny, 2007).

El asunto de análisis se centra en que la modificación de las fronteras tradicionales entre el sistema judicial y el sistema político en las sociedad democráticas, tiene un profundo impacto en la forma de concebir el derecho, y las relaciones entre la sociedad y el Estado, implica un tenso reajuste entre las dinámicas de fuerza entre minorías y mayorías, el hecho de que sea judicial y no Política, la exigencia de respeto a los derechos fundamentales que las minorías hacen a la mayoría, produce un cambio en la forma como se legitiman la ley y las Políticas públicas, cambio producido por el sesgo que sufre el consenso mayoritario para definir temas que interesan a la sociedad en general, de ahí que bien dice Uprimny "con la judicialización de la Política las batallas o conflictos políticos que antes se definían por consenso democrático ahora se definen mediante sentencia por un juez constitucional". (Uprimny, 2007)

Siendo así, resulta entonces pertinente la pregunta que se hace Uprimny ¿Es democráticamente deseable la judicialización de la Política? A lo que manifiesta en las últimas dos décadas, que se han conocido 
formas de judicialización de la política importantes en numerosos campos, pero tal vez los más significativos han sido los siguientes:

1. La lucha contra la corrupción Política y por la transformación de las prácticas Políticas;

2. El control a los excesos gubernamentales, en especial en los estados de excepción;

3. La protección de grupos minoritarios y de la autonomía individual;

4. La protección de poblaciones estigmatizadas o en situaciones de debilidad manifiesta;

5. El manejo de la Política económica, debido a la protección judicial de los derechos sociales. (Uprimny, 2007)

No se requiere mayor formación política ni jurídica para darse cuenta que según lo que dice un experto en el tema como Rodrigo Uprimny, en Colombia se han judicializado cinco ejes problémicos que definen perfectamente el núcleo de la crisis político-social que atraviesa el país, esto quiere decir, en clave de la judicialización de la Política, que problemas de alto impacto social vinculados con la corrupción, la violación de derechos humanos y el infortunado manejo de la economía del país, que antes esperaba resolver Políticamente la sociedad mediante el juego democrático, el debate público, las Políticas públicas y la discusión Política de la ley, ahora, en gran medida, se vuelven asuntos a resolver mediante sentencia, es decir, la solución a la crisis se volvió un asunto de abogados principalmente.

Según Uprimny (2007), tanta responsabilidad en cabeza del poder judicial por exceso en la judicialización de la Política puede representar unos riesgos democráticos que él describe así:

Sobrecarga del aparato judicial, que empieza a asumir con dificultad tareas que no le corresponden totalmente. Así, la transferencia de la resolución de demasiados problemas a los jueces puede terminar por afectar la propia legitimidad de la administración de justicia, que no tiene en el largo plazo la capacidad de enfrentar tales retos. s. Y eso deriva no sólo de la cantidad de problemas que empieza a resolver el sistema judicial sino también al tipo de asuntos, por cuanto frente a determinados conflictos, la arena judicial puede no ser la más apropiada. Los riesgos de error judicial son grandes. 
La judicialización de los conflictos políticos tiende casi inevitablemente a politizar, en el mal sentido del término, los conflictos judiciales, pues los tribunales y los procesos se convierten en escenarios e instrumentos de estrategias de actores políticos, lo cual desestabiliza en forma profunda el rol del sistema judicial como garante de los derechos de las personas y de las reglas de juego democráticas.

El derecho deja de ser la regla general que toda la comunidad reconoce, pues el sentido de las normas se considera manipulable según los intereses. La opinión empieza entonces a desconfiar de toda decisión judicial, con lo cual se compromete la legitimidad misma de la administración de justicia. Y esto es aún más grave en democracias precarias, pues en ellas la independencia del poder judicial dista de estar consolidada (Uprimny, 2007)

Finalmente, el constitucionalista en mención, que la judicialización de la Política tiene potencialidades, pero igualmente riesgos. El desafío es entonces potenciar sus posibilidades democráticas y minimizar sus efectos perversos, lo cual, desde el punto de vista académico, debería llevarnos a tratar de investigar más específicamente cuáles son las judicializaciones democratizantes y cuáles, por el contrario, son democráticamente riesgosas. Para concluir éste punto, la judicialización de la Política puede reportar socialmente beneficios o perjuicios, y los últimos están asociados a riesgos que se verifican en la realidad Política en la medida en que por ejemplo si se llegase a presentar la deslegitimación de la administración de justicia, la solución a tal problema no podría ser jurídica sino Política, de manera que cuando un Tribunal constitucional va a tomar una decisión su responsabilidad va hasta anticipar los efectos políticos que ésta pueda tener es decir, debe tener entonces el operador judicial solidas competencias en el dominio de la ciencia Política, ahora, siendo claro que el juez debe tener una formación profesional en Política y que en Colombia los jueces no tienen una formación exclusiva como abogado destinados a ser jueces, toda vez que se supone que todo abogado debe tener las competencias mínimamente necesarias para desempeñarse como juez, no es difícil comprender que el cambio de ideología en el paradigma constitucional cuestiona la formación de los abogados en general.

Así las cosas, el cambio en la ideología del paradigma constitucional, ha traído enormes cambios en la forma como los abogados piensan 
y actúan en su ejercicio profesional. El desarrollo y la vigencia de la Carta Política del 91 ha significado un replanteamiento general de distintos y trascendentales temas e instituciones político - jurídicas, y ha obligado tanto a los estudiosos de la academia en general como a los profesionales del Derecho, a introducir un conjunto de explicaciones, doctrinas, conceptos y prácticas hasta entonces poco conocidas en el diario devenir de la construcción del derecho colombiano, lo que hace que la práctica diaria del derecho se convierta en un reto permanente que implica una variación drástica de sus categorías mentales, la cuales en sus líneas fundamentales representan un duro quiebre con la tradición del pensamiento jurídico, arraigado principalmente en el formalismo jurídico, la previsión o plenitud del ordenamiento, la coherencia interna de sus disposiciones, el legalismo y la operación lógico-deductiva de la interpretación del Derecho.

Hoy día, el abogado se enfrenta a una práctica profesional más compleja porque se debe preguntar por la moralidad del derecho que aplica y por sus efectos sociales y políticos, siendo esto valido sin distingo de si se es operador de la justicia, abogado litigando, abogado asesor de empresas, funcionario público etc., esto porque como se mencionó con anterioridad, todo el derecho se constitucionalizó de manera que ahora las soluciones que debe plantear el togado desde el ejercicio de su profesión no serán solo jurídicas, sino que tendrá también que responder en la prestación de sus servicios profesionales por el manejo de unas competencias que le permitan presentar a su cliente, si es en el sector privado, alternativas de solución que partan también de la comprensión e interpretación de los principios y valores constitucionales, es decir, deberá conocer disciplinariamente los fundamentos políticos de la Constitución, lo mismo si se es funcionario público, abogado litigante etc.

Contextualizadas las exigencias constitucionales del "nuevo derecho" y las implicaciones axiológicas y Políticas que éste impone en la práctica del derecho, se pasa entonces a reflexionar sobre el impacto que tiene el cambio ideológico de paradigma constitucional en la formación del abogado, particularmente en la práctica de consultorio jurídico.

Ya hace un tiempo, desde antes incluso de que entrara en vigencia la Constitución de 1991, se advertía lo anacrónico que resultaba ser el consultorio jurídico como escenario de práctica de formación de los estudiantes de derecho. La calidad de abogados de pobres, que caracteriza la práctica de consultorio jurídico de los estudiantes de 
derecho del año 1971, reafirmada luego mediante la, con este condición que se le impone al estudiante de derecho pretende el legislador imprimir en la formación del abogado unos valores asociados con la vocación social, directamente relacionada con la proyección social, como servicio social, que debe tener toda universidad en Colombia, en este sentido, se establecieron una serie de competencia para que los estudiantes de derecho en sus prácticas facilitaran el acceso a la justicia de personas de escasos recursos económicos (pobres) sin posibilidad de contratar los servicios de un abogado, de manera que los estudiantes, fueron habilitados para representar a los pobres en ciertos asuntos y bajo determinadas condiciones específicas.

El hecho es que con el paso del tiempo se fue haciendo evidente que la forma como la ley concibe la práctica de consultorio jurídico resulta ser ineficiente para desarrollar las competencias que deben ser del dominio de los abogados, pero así mismo, se pudo determinar qué tal como está legalmente regulado el consultorio jurídico, es poco el aporte que este hace, al proceso de formación de abogados capaces de jalonar un verdadero cambio social que nos lleve a concebir una convivencia pacífica, justa y equitativa. El concebir al estudiante de derecho como un estudiante de pobres, realmente antes que favorecer una formación adecuada en valores, lo que genera es la creencia perjudicial de que mejorar la condición de vida de los "pobres" es un trabajo de caridad, propiciando que el futuro abogado desde su práctica de derecho desligue por completo la realidad del "pobre" con la suya, es decir, no se asume el consultorio jurídico como una práctica en la que debe el estudiante desarrollar unas competencias que le permitan ser creativo y propositivo frente a las alternativas de oportunidad de un verdadero cambio social.

Para ser más explícito sin lugar a dudas se puede afirmar que desde la proyección social unas son las competencias y valores humanos que desarrollan el sentido de la responsabilidad social con las personas carentes de recursos económicos (pobres) y otras las competencias disciplinares que desde la ciencia Política y la axiología, otorgan al estudiante de derecho una serie de conocimiento y destrezas que lo facultan para hacer un abordaje de la realidad desde la complejidad de lo social, cultural, político, económico y jurídico, con tal dominio y experticia que les permitan convertirse a través del quehacer diario del derecho en verdaderos agentes de materialización de las promesas de mejor vivir que contiene la Constitución Política. 
Hasta este punto se ha querido mostrar que una de los grandes retos que tienen los consultorios jurídicos es la necesidad de imprimir al escenario de práctica de los estudiantes de derecho, la posibilidad de que frente a la judicialización de la Política, reaccionen como verdaderos actores protagónicos con una real potencia intelectual para generar cambios en su realidad, lo que no se consigue sólo con una instrucción jurídica, ya que la crisis actual en la que se encuentra sumida la sociedad y el Estado colombiano debe ser abordada por los estudiantes de derecho con una actitud clara de generar movilización Política en la comunidad y esto sólo se podrá logar con una acertada y disciplinar formación del Estudiante de Derecho en Ciencias Políticas.

La anterior reflexión por lógica y coherente parece no contener mayor dificultad en su implementación, es decir, si la Política se judicializa, quiere decir que ahora la Política es objeto de estudio de los abogados, en consecuencia, parece ser obvio que ahora la enseñanza del derecho, como ciencia social, debe modificar el diseño del syllabus de tal suerte que se incluyan en este las competencias propias de la ciencia Política, sin embargo, esto que parecería ser obvio no lo es precisamente porque la judicialización de la Política es un fenómeno complejo que parte del hecho de que existe una relación connatural entre Política y derecho la cual es abordada desde la ciencia jurídica, es decir, no es posible pensar en un orden jurídico desligado de las categorías Políticas, de ahí que tradicionalmente en el programa de derecho se estudien asignaturas como teoría del estado, historia de las ideas Políticas, Políticas públicas, y otras similares que tienen por objetivo el estudio de las dinámicas de poder en la sociedad como origen del Estado y del ordenamiento jurídico, siendo así entonces ¿A que hace referencia la judicialización de la Política y la formación Política del abogado? En este orden de ideas, lo primero entonces sería definir: ¿Qué competencias de la ciencia Política debe disciplinariamente tener el abogado y que actualmente no están presentes en su formación? ¿Cuáles de las anteriores competencias son las requeridas para enfrentar la moralización y la politización del derecho? ¿Cómo se deben enseñar las competencias propias de la ciencia Política en clave de la ciencia jurídica? ¿Como se materializa la práctica en el consultorio jurídico de la judicialización de la Política? ¿Cómo se entrena el estudiante de consultorio en el ejercicio de las competencias que le permitirán resolver conflictos desde la judicialización de la Política?

El asunto no es fácil de resolver porque la ciencia Política no es una ciencia social "decantada" en su objeto disciplinar, en sus contenidos 
y metodología de enseñanza, al respecto el politólogo Javier Duque Daza, citando a David Laitin sostiene que el panorama para la Ciencia Política es confuso porque además de las disputas intelectuales respecto al objeto cualificante de la Ciencia Política y de los enfoques teóricos múltiples y en ocasiones contrapuestos, en los desarrollos de la ciencia Política en el último medio siglo se han multiplicado las líneas, las áreas y los subcampos disciplinares de tal forma que se ha llegado a plantear, como lo hace Laitin (2004) que existe una anarquía y un caos disciplinar. Esta multiplicidad de orientaciones, contenidos, temáticas y líneas académicas se expresan no solo en la investigación y en los eventos nacionales e internacionales de la disciplina, sino también en los planes de estudio y en las estructuras curriculares de los programas de pregrado o licenciatura de Ciencia Política.

Finalmente, Laitin plantea algunas reflexiones en cuanto a las dificultades que presenta la enseñanza de la Política como ciencia. Dice Laitin (2004), citado por Daza (2014):

a) No existe un curso introductorio estándar en ciencia Política que ubique en los rudimentos y aproxime a los estudiantes a ciertos acuerdos de la disciplina, líneas, autores y enfoques; b) no hay una orientación que permita unificar los currículos con ciertos estándares, ni siquiera de forma parcial. Cada escuela produce sus politólogos con sus orientaciones, énfasis y modos particulares de ver la disciplina; c) en muy pocos casos existen prerrequisitos para los cursos superiores, lo cual hace que los profesores se enfrenten a estudiantes con diversos niveles de formación que no cuentan con los fundamentos necesarios para avanzar de forma significativa; d) existe una alta fragmentación en enfoques, teorías y metodologías, con lo cual impera una imagen de ausencia de un núcleo disciplinar, de autores centrales y clásicos. La imagen de la disciplina era la de un espejo trizado en múltiples partes, sin que pudiera reflejarse algo claro en él.

Con lo anterior se concluye que la formación Política del abogado no es asunto de incluir en la malla curricular unas asignaturas referidas a un mero contenido político, sino que se trata de que verdaderamente el abogado adquiera competencias que le permitan observar, analizar y comprender la realidad como politólogo, y si se tiene en cuenta que la ciencia Política como disciplina autónoma resulta ser en alto grado controversial, no resulta difícil percibir que es grande el reto que tienen 
los consultorio jurídicos de diseñar escenarios de práctica jurídicoPolítica que realmente permita al estudiante adquirir unas competencias y conocimientos que lo capaciten para abordar eficientemente los conflictos de la sociedad.

\section{De la moralización del derecho y la formación axiológica del abogado}

Leonardo García Jaramillo, estudioso conocedor del neoconstitucionalismo en Colombia, en un artículo de su autoría titulado - El "nuevo derecho" en Colombia: ¿Entelequia innecesaria o novedad pertinente? Describe perfectamente la moralización del derecho por cuenta del Neoconstitucionalismo, cuando al caracterizar al juez Neoconstitucional lo presenta como un profesional del derecho con una sólida formación en valores que moralmente demarcan sus decisiones al punto de estar autorizado constitucionalmente para apartarse de la ley cuando su juicio moral así se lo indique, es así que García Jaramillo para referirse al juez Neoconstitucional, comienza citando a un férreo crítico del Neoconstitucionalismo, García Amado (2008), quien se refiere al juez del Neoconstitucionalismo diciendo: "la clave de la práctica jurídica sigue estando en la conciencia del juez, pero ésta ya no es conciencia cognoscente, sino libérrima conciencia decisoria; el juez ya no es contemplado como servidor de la ley sino como señor absoluto del derecho".

Posteriormente continúa García Jaramillo (2008) diciendo:

Si en algún funcionario recae la responsabilidad de concretar el nuevo derecho y dotarlo de fuerza normativa eficaz es en el juez. Pero no ya aquel tipo de juez descrito adecuadamente en su momento como integrante de la rama menos peligrosa del sistema jurídico y, mucho menos, como aquel que debe limitarse a ser la boca que pronuncia las palabras de la ley, como lo pensó Montesquieu, sino un funcionario que no es ya el orientador de unos ritualismos procesales vacíos de contenido, ni menos el inflexible fiscalizador del cumplimiento de los rigores de la ley. (...) Casi desde el inicio mismo del cambio constitucional en 1991 se abogó por la demanda a un tipo distinto de juez respecto del administrador de justicia que ejercía su cargo siguiendo los lineamientos de la Constitución del 86. Como afirma Carlos Gaviria: "Cuando se dio la Constitución del 91, una de las mayores virtudes que en ella advertí fue la exigencia implícita de un nuevo juez colombiano. Que no se nutra 
sólo de incisos y parágrafos incitantes a la hermenéutica (¿o no hermenéutica?) exegética, sino de reflexiones que le permitan descifrar la clave de un universo axiológico tan apasionante y complejo como el que acoge nuestra Carta".

El juez que responde a las exigencias del Estado social de derecho y no desentona con el nivel implícitamente impuesto por la jurisprudencia constitucional, es el que además de conocer la legislación y aplicarla sin prevaricar, cometer faltas disciplinarias o delitos (cohecho, concusión o tráfico de influencias, por ejemplo), ha desarrollado o vinculado a su labor ciertas virtudes, tales como valentía y discreción para ejercer debidamente su función, y coraje para enfrentar los riesgos que acaecen; imparcialidad respecto a sus juicios e independencia frente a las partes, sus colegas, las otras ramas del poder público y los medios; un juez sin prejuicios ni pactos burocráticos. Un juez con la capacidad tanto de conmiseración para aproximarse al problema como de ponderar adecuadamente los pros y contras en los casos en los que hay altos costos morales para una de las partes o para la sociedad; y consciente de la necesidad de capacitarse permanentemente, que rinda en lo cuantitativo sin ir en demérito de lo cualitativo es decir, no quiere decir García Jaramillo cosa distinta a que el abogado como juez neoconstitucional debe tener una clara conciencia axiológica del poder que tiene, para no ceder ante la tentación de sentirse dueño absoluto del derecho y cometer los abusos que hoy se cometen incluso en nuestras altas Cortes.

La formación axiológica del abogado tiene una complejidad similar a la que presenta su instrucción Política, toda vez que de la misma manera en que existe una estrecha relación entre el derecho y la Política y no por eso la formación tradicional del abogado lo hace politólogo, de esa misma manera existe una estrecha relación entre el derecho y los valores sin que esto implique actualmente que un profesional en derecho en su formación, haya tenido instrucción en el fortalecimiento de las competencia que le permiten tener una comprensión axiológica del impacto que socialmente tiene el ejercicio de su carrera.

La preocupación por la formación en valores de los abogados no es asunto nuevo, de hecho, en términos generales en Colombia ha sido una preocupación constante la formación en valores en la educación superior, de hecho los teóricos de la educación, sin discusión han aceptado que la formación universitaria debe estar comprometida con el desarrollo moral de los estudiantes de una manera mucho más 
intencionalmente pensada, determinada, decidida y planificada, que la mera mención del compromiso ético como competencia personal. A ello han de dirigir conjuntamente su esfuerzo todos los sectores implicados: los responsables y actores del mundo universitario; los representantes de la vida social y cultural; los empresarios, las administraciones, etcétera.

Por tanto, diría Buxarrais (2004):

El aprendizaje universitario no debería ser la mera instrucción disciplinar. La práctica profesional sin moralidad puede ser desastroso para la comunidad y penoso para aquellos que de tal modo ejerzan como médicos, ingenieros, arquitectos etc., con aparente "éxito personal" pero inútiles o nocivos para la sociedad. El aprendizaje que nos habilita para ejercer una profesión debería ir acompañado del aprendizaje ético que nos permite ejercer la ciudadanía.

Para Cáceres García el profesional ha de ser un experto competente en su especialidad $y$, al mismo tiempo, una persona moralmente madura. Competencia y moralidad, unidas, están dotadas de una fuerza muy potente como motor de las personas, en la misma medida en que configuran y determinan la necesidad de autoestima positiva. Esto no sólo está vinculado a los sistemas de actitudes y valores, sino que, además, es nuclear en la construcción de la propia identidad. El desarrollo de ambos aspectos -competencia y moralidad, retroalimentándose mutuamentevendrá a revertir en el crecimiento humano y en la satisfacción personal, al mismo tiempo que en el desempeño laboral y en el cumplimiento de los objetivos propios del interés general.

En consecuencia, frente a otros modelos centrados en el saber técnico y excluyente de valores relacionados con el desarrollo personal y moral, la formación universitaria ha de contemplar el crecimiento de la persona en todos los aspectos mencionados. En el marco de la educación superior, la formación profesionalizante ha de implicar a la persona entera, lo que es tanto como decir que debe desarrollar las diferentes dimensiones humanas, en lugar de centrarse únicamente en aspectos técnicos. Desde un punto de vista axiológico e integral, los valores han de fundamentar y guiar el desarrollo de competencias para la empleabilidad que las universidades han de procurar, de cara a una formación igualmente satisfactoria para la sociedad, para el mundo laboral y para los individuos, desde un punto de vista humano. 
Siendo así las cosas, ¿Qué sucede entonces, si la necesidad de formar en valores a los futuros profesionales se ha identificado como una urgente prioridad, porque aún no se logra el cumplimiento de este objetivo? Guerrero Useda (2006), plantea que "algunas claves para responder esta pregunta se encuentran en el texto de Escámez la Ética profesional del mediador de familia y de Perilla y Guerrero "La oportunidad del enfoque de las competencias y la desigual competencia por las oportunidades escolares y laborales", los cuales están relacionados con la didáctica, las condiciones de enseñanza y el conocimiento pedagógico del contenido.

El estado de las investigaciones muestra que la formación moral, en cuanto contenido, se caracteriza por demandar conocimientos pedagógicos de alto nivel, a la vez que estudios como el de Mesa y Suárez (2006) "Formación de la conciencia moral: desafío para la educación superior", muestran universitarios que no alcanzan estructuras superiores de juicio moral estando cercanos a graduarse y el medio muestra que la crisis de valores y la creciente corrupción en las instituciones devela que ante la autoridad y la jurisdicción los profesionales no están en capacidad de sobreponer recursos. Así las cosas, la enseñanza de la ética y la educación moral se descubren como contenidos que requieren una enseñanza educativa.

Finalmente dice Guerrero Useda que el problema no se reduce a la apertura de un espacio propio en el currículo para los contenidos relacionados con los valores, ni al diseño estructurado de temarios. Estos contenidos demandan una enseñanza que, superando lo descriptivo y lo enunciativo, lleve a los estudiantes a la maduración de estructuras superiores y universales de juicio y razonamiento moral. De ahí la fuerza del clamor de intelectuales como Domingo-Moratalla (2010) "Ética de las profesiones y formación universitaria: tres modelos de responsabilidad profesional", pida introducir una mínima cultura moral en los planes universitarios.

Pues bien, si se ha identificado un problema con la formación de valores en la educación superior, el problema con la formación del abogado es aún de mayor significancia, en la medida en que el Estado Colombiano tiene por esencia de su naturaleza la misión de garantizarnos, con el poder que se le ha instituido, un orden social que nos permita convivir en paz, en condiciones dignas que garanticen nuestro derechos fundamentales y sociales, así mismo el acuerdo social plasmado en la Constitución Política, establece que el Estado en el ejercicio de su poder sólo podrá hacer lo que la ley y la Constitución 
le permiten, es decir, que el Estado en todas sus actuaciones estará sometido y limitado por el ordenamiento jurídico, siendo así las cosas se hace evidente que principalmente recae sobre los abogados, la responsabilidad Política y social de velar porque el Estado cuente con la estructura jurídica pertinente y apta para cumplir sus funciones y así mismo, la sociedad espera que los abogados diseñen las herramientas jurídicamente adecuadas para poder ejercer los derechos políticos que garantizan el sometimiento del Estado al ordenamiento jurídico.

A esta altura de la reflexión que se viene haciendo parece ser obvio que el abogado requiere hoy en día una formación disciplinar politológica y axiológica. La formación axiológica del estudiante de derecho implica para el docente enseñar y comprender que el Derecho, es más que un sistema de normas jurídicas establecidas y sancionadas por el Estado, pues traduce como voluntad Política, las condiciones esenciales (materiales y espirituales) de una sociedad de clases, cuya voluntad Política suelen sintetizarse en los valores fundamentales como fórmula de consenso social de la o las clases dominantes y sus sectores más influyentes, significa ver al Derecho con su gran carga axiológica; como un portador de valores.

La formación en valores, está directamente vinculada con la dimensión estética y técnica, así mismo al prestigio profesional como fin deontológico de la ciencia del derecho, esto es así porque para que los juristas puedan cumplir debidamente su función necesitan crear credibilidad y confianza en la sociedad, debe ser un profesional "prestigioso". No se puede encomendar la justicia al hombre y a la mujer injusta. La pertinencia socio cultural de los profesionales del Derecho en la Educación Superior se logra a través de un proceso de formación axiológica, desde una generalización de experiencias culturales que den cuenta de la flexibilidad cultural, y la profundización de la profesión, según Pupo (2016) y en donde se ven reflejados valores como; el humanismo, la honestidad, la cortesía y respeto en sus relaciones, la independencia, la solidaridad y el sentido de la justicia y la equidad, que a la vez conduce a hacer que prevalezca en la solución de los conflictos un profundo sentimiento de equidad y justicia, manteniendo el respeto hacia las personas con quien sostiene relaciones con motivo de su trabajo. 


\section{Innovación social universitaria en la formación del abogado}

Reconocida la necesidad de generar un cambio en el paradigma de la enseñanza del derecho, y las terribles implicaciones sociales, Políticas, ambientales y económicas que tiene para la sociedad no hacerlo, se hace obligado repensar la misión de la universidad y su responsabilidad, es decir, es necesario pensar la formación del abogado como un proceso que requiere estrategias pedagógicas de "innovación social universitaria" que ofrezcan nuevas alternativas que permitan superar las dificultades que actualmente tiene el modelo tradicional de formación de los abogados para desarrollar competencias que permitan un eficiente desempeño de éstos en la comprensión y resolución de conflictos sociales, jurídicos, políticos y axiológicos. ¿Si ya hace mucho tiempo se sabe que la formación de abogado es por competencias entonces donde radica el problemas?, pasamos a aprendizaje servicio colaborativo.

\section{Conclusión}

Parafraseando al doctor Héctor Velásquez Posada, quien haciendo un estudio crítico de los consultorios jurídicos acertadamente planteo la falta de pertinencia de estos con la realidad político-social actual así: "En ocasiones, caemos en el "sofisma de MacGiver", que consiste en pensar que en todos los campos del conocimiento se puede hacer lo que hacía este personaje de la televisión del siglo pasado, quien, con una navaja y elementos de la vida diaria, lograba resolver todos los problemas que se le presentaban y salía airoso de todas sus dificultades. Eso mismo es lo que pasa cuando nos convencemos que con solo otorgarle al estudiante la facultad de presentar unas limitadas demandas ante un juez municipal en única instancia, con ello le va a bastar para resolver todas las necesidades del ciudadano.

Hacerle creer a la comunidad que las escuelas de Derecho con la sola instrucción y formación disciplinar en ciencia jurídica, desarrollan en los estudiantes de Derecho las competencias necesarias para impactar la realidad generando un verdadero cambio social, es un falacia que pretendemos que la sociedad, y nuestros estudiantes, crean, porque en realidad, con la nueva Constitución de 1991, en Colombia la teoría pura del derecho se desvaneció, a partir de 1991 particularmente en Colombia el derecho se tornó moral y político, es decir, que no basta con tener un dominio disciplinar en la ciencia del derecho, también debe tenerse el conocimiento y adiestramiento científico que permita el estudio de las 
dinámicas de relación que se dan entre la ciencia política, la moral y el derecho, es decir, la formación del abogado debe procurar una práctica en la que se desarrollen competencias en torno a lo que Dra. Edith González Palmira denomina teorización sistematizada de la relación entre la Política, como forma de actividad, y la axiología, entendida como la ciencia que versa sobre el estudio de los valores en su dimensión ética para contribuir al desarrollo de la actividad Política.

\section{Referencias}

Aguilar, G; Gajardo, B y León, A (2015). Equidad, inclusión social y democracia: una respuesta crítica a los argumentos en contra del activismo judicial. Estudios constitucionales [online], vol.13, n.1 [citado 2017-11-07], pp.373-398.

Buxarrais, M. R. (2004). El aprendizaje ético y la formación universitaria más allá de la casualidad. Teoría de la Educación. Revista Interuniversitaria, 16, 91-108.

Casares, P., Carmona O., \& Martinez-Rodriguez, F. (2017) Valores profesionales en la formación universitaria. REDIE [online]. 2010, vol.12, n.spe [citado 2017-11-08], pp.1-15. ISSN 1607-4041. Disponible en http://www.scielo.org.mx/scielo.php?script=sci_arttext\&pi$\mathrm{d}=$ S160740412010000300004\&lng=es\&nrm=iso

Duharte, E. (2006) y coautores: La Política: Miradas Cruzadas, Editorial de Ciencias Sociales, La Habana.

Duque, J. (2014). La ciencia Política en Colombia. Análisis de los planes de estudio, sus áreas y sus énfasis. Political science in Colombia. Analysis of its curriculum, areas of study and emphasis. Pap.polit. [online]. 2014, vol.19, n.2, pp.377-411. ISSN 0122-4409. http://dx. doi.org/10.11144/Javeriana.PAPO19-2.nppj.

Dworkin, R. (1997). Los derechos en serio. Barcelona: Ariel.

Escámez, J. (2006). La ética profesional del mediador familiar. En A. Hirsch, Educación, valores y desarrollo moral: Vol. 1. Valores de los estudiantes universitarios y del profesorado (pp. 49-71). México: Gernika.

Hamilton A. (1962), El Federalista, No 78. The Least Dangerous Branch. The Suprema Court at the Bar of Politics. 
García, E. (2004). Infancia. De los derechos y de la justicia, $2^{a}$ edición actualizada, Editores del Puerto, Buenos Aires

García J, L. (2008). El "nuevo derecho "en Colombia ¿Entelequia inncesaria o novedad pertinente? Revista Derecho(29), 289-330.

Guerrero-Useda, M. E. (2002). Enseñanza educativa de las matemáticas. Fundamentos de la matemática universitaria (pp. 101-110.). Bogotá: Escuela Colombiana de Ingeniería.

Gonzalo, A. C. (2015). Equidad inclusión social y democracia: una respuesta crítica en contra del activismo judicial. Esudios Constitucionales, vol. 13(1), 373-398. Recuperado el 2017-11-07

Laitin, D. (2004). The Political Science Discipline. En Mansfield, E. D. y Sisson, R. Democracy, autonomy, and conflict in comparative and international politics (pp. 11-40). Columbus: Ohio State University Press.

Mesa, J. L. y Suárez, G. A. (2006). Formación de la conciencia moral: desafío para la educación superior. Actualidades Pedagógicas, 49, 23-32.

Parra (2002). El nuevo derecho societario Bogotá: Universidad Externado de Colombia/ Barcelona: Bosch \& Medellín: Biblioteca Jurídica DIKE.

Pupo K. (2016) Estrategia para la formación axiológica del jurista en la Educación Superior.

Revista internacional de derechos humanos la judicialización de la Política en Colombia: casos, potencialidades y riesgos - Rodrigo Uprimny Yepes http://www.scielo.br/pdf/sur/v4n6/es_a04v4n6. pdf

Uprimny, R. (2007). La judicialización de la política en Colombia. Sur Revista Internacional De Derechos Humanos (6), 52-59. Obtenido de http://www.scielo.br/pdf/sur/v4n6/es_a04v4n6.pdf 